\title{
Living According to Conscience
}

\author{
ELVIO BACCARINI, JULIJA PERHAT \\ Faculty of Humanities and Social Sciences, Rijeka
}

\begin{abstract}
Summary
We discuss the proposal of Chandran Kukathas engaged in one of the goals of liberal theories: the protection of freedom of conscience. Kukathas proposes the metaphor of a liberal archipelago where different communities are sovereign in enforcing their worldview on their territory. We share Kukathas's intention to strongly protect freedom of conscience, but we think that $\mathrm{Ku}$ kathas's theory fails to adequately protect it. In Kukathas's view, freedom of conscience is protected through freedom of association and the related freedom to exit an association. But freedom of exit, intended only as a right not to be coerced when one wants to leave, is insufficient. It must be sustained by the provision of capabilities to leave that one can exercise, as well as by capabilities to evaluate her condition. We discuss, then, a more promising proposal of an egalitarian libertarian archipelago proposed by Michael Otsuka. After explaining why this system isn't sufficiently stable, we conclude that the constitutional egalitarian liberal state is a better candidate.
\end{abstract}

Keywords: Autonomy, Equality, Archipelago Liberalism, Freedom of Conscience, Freedom of Exit

\section{Introduction}

The problem we are concerned with regards freedom to live according to conscience. Several authors remark its relevance, and among them are authors that we

1 This work has been fully supported by the University of Rijeka under the project uniri-human-18-151. We thank all colleagues who helped us improve earlier drafts with useful comments and suggestions, primarily Prof. Chandran Kukathas and other participants at the symposium dedicated to The Liberal Archipelago organized by the Croatian Society for Analytic Philosophy, the Department of Philosophy and the Department of Cultural Studies of the University of Rijeka on January $27^{\text {th }}, 2012$. We are also thankful to Prof. Michael Otsuka and other participants at the symposium dedicated to his work at the Summer School "Equality and Citizenship", University of Rijeka, the Center for Advanced Studies of South East Europe, and the Faculty of Humanities and Social Sciences of Rijeka, June $29^{\text {th }}$ to July $3^{\text {rd }}, 2015$. We would like as well to thank the reviewers for their useful comments. 
discuss in this paper. Our central focus is on Chandran Kukathas's proposal. He claims that conscience is the most important human motivation (Kukathas, 2003, pp. 48-49). It is respected when individuals are not forced to live in a way they cannot, in good conscience, accept (ibid., pp. 113-114). The problem that worries liberal authors is that even in democratic societies freedom of conscience is threatened in various ways. At the dawn of democracy, John Stuart Mill wrote about threats to it that derive from the possibility that majorities impose their worldviews on minorities, either through state's institutions or by social pressure (Mill, 1859, 1861). This is the inspiration of Kukathas's theory as well. His solution is represented by a society where no supreme authority can force its worldview upon the communities that do not endorse it. Instead, the society is organized like an archipelago of communities and associations that live in accordance with their favourite worldviews. People are free to associate in groups that practice the worldviews that they endorse. Conscience is protected in virtue of two aspects: the freedom of individuals to associate with those who share their worldviews (and the corresponding freedom to dissociate from those with whom they have incompatible worldviews) and the mutual tolerance between these associations.

We share Kukathas's intention to strongly protect freedom of conscience. But we think that the model of social organisation that he proposes is inadequate for this aim. The reason is that his model is not suitable for the fair protection of individuals' conscience and their freedom of exit because of the insufficient support given to capabilities needed to exercise this freedom. An extended presentation and discussion of such communities that exist in practice, and in judicial cases, is shown by Brian Barry (2001). Such are, for example, communities that impede good education for their children by saying that it is not needed for their traditional way of life. In some communities, women are not treated equally in relation to education, or even divorce. In the most horrible cases girls are victims of irreversible genital mutilation. We think that one of the wrongs of such practices is hindering capabilities to exercise freedom of exit, and thus freedom of conscience. Instead of Kukathas's archipelago, we think that a more appropriate protection of freedom of conscience is still provided by the liberal society represented by a state that, through its constitution, laws and institutions, exercises sovereignty and protects basic rights, liberties and opportunities, as well as ensures means to make effective use of them (Rawls, 2005, p. 6). Such a society represents a better context for the exercise of freedom of conscience, because it supports capabilities to exercise choices needed for its effective implementation. The solution, clearly, will not be satisfactory for all members of the community. For example, those persons and communities who think that their duty is represented only by the preservation of a particular worldview will be dissatisfied with a society that sustains capability for effective exercise of choice, and will be impeded to live entirely according to their conscience. We think that a society where 
all persons live entirely according to their conscience is not possible. Instead, the appropriate aim is to shape a society where people can fairly live according to their conscience. This is not obtained by Kukathas's proposal because such capabilities are ensured only for powerful members of society. This limits the capabilities of other members to make effective choices, and thus to live according to their conscience when they disagree with the worldview dominant in the community. This way, the freedom to live according to conscience is only contingently present for other members of the society. This happens when they agree with the powerful members of society. Other members live according to the conscience of the powerful, and not in accordance with their own conscience. To summarize, the egalitarian liberal state is preferable because the protection that it offers to basic rights, liberties and opportunities, and means to make effective use of them, is needed for sustaining the capabilities required to fairly protect freedom of conscience. The freedom of conscience of those members of society who reject the liberal worldview is protected in the sense that they are not obligated to comprehensively organize their lives in accordance with such a conception. They are free to associate with persons who share their worldview and form corresponding communities. Yet, they are not allowed to complain regarding policies that support persons to develop capabilities that permit them to make different choices. This constitutes a limit to freedom of conscience of some of the illiberal members of society. However, the limit is justified because it is needed in order to ensure fair freedom of conscience among all members of society.

First, we are going to present a more detailed overview of Kukathas's proposal. Then we point out what is missing in his theory, some of the necessary elements being freedom of association, freedom to leave, and, thus, freedom of conscience. Finally, we discuss Otsuka's proposal that represents an egalitarian libertarian archipelago that includes a substantial right to exit. We deem it as a more promising proposal than Kukathas's. However, in the end, we side with the proposal of a constitutional democracy due to the instability of Otsuka's proposal.

\section{Kukathas's Theory: The Archipelago}

Kukathas's metaphor of liberal archipelago where different communities mutually tolerate each other "is a society of societies which is neither the creation nor the object of control of any single authority" (Kukathas, 2003, pp. 8-9). Contrary to the classical sovereign liberal state, this is a society which will be "a collection of communities (and, so, authorities) associated under laws which recognize the freedom of individuals to associate as, and with whom, they wish" (ibid., p. 20). Each society that constitutes the society of societies is internally sovereign in the choices of its worldview and organized according to the will of its members (in the remaining part of the paper the society of societies will be called 'society', and the societies 
that constitute it will be called 'community' or 'association'). In Kukathas's view, the archipelago ensures better protection of freedom of conscience than classic democracies through their constitutions and basic institutions protective of equality and basic rights and liberties. This is because Kukathas makes it clear that not all associations in a liberal society value freedom and equality. Thus, enforcing the system of rights, liberties, opportunities and equality of constitutional democracies over them would represent forcing them to live in a way that they cannot, in good conscience, accept. This is why such communities must be free to create different organizations that correspond to their worldviews. If individuals wish to continue to live by the terms of these associations, even when they limit freedom and do not recognize equality, the outside community has no right to intervene. Communities may exist as long as their members decide to remain members, i.e., if they do not decide to leave the community.

Freedom of conscience in Kukathas's society is ensured because individuals will be free to reject the authority of one association when they do not think of it as a good frame for their conscience, and to place themselves under the authority of another. Thus, the central liberal entitlements in the political society described by $\mathrm{Ku}-$ kathas are freedom of association, as well as its corollary, freedom of dissociation, or, in other words, the freedom of exit (ibid., pp. 28-29, 74-76). These are supported by the prohibitions of slavery and physical coercion (Kukathas, 1992, p. 128). This is everything that is needed in order to protect freedom of conscience of persons, and these are the only limits put to communities' authority over its members. In addition, as regards the relation between these communities, there is the principle of mutual toleration among them (Kukathas, 2003, p. 25).

When it comes to the question of children's rights in a community, although Kukathas concedes that his conclusion is troublesome, he admits that, coherent with his theory, there can be no limits to parents' actions in these issues: "In such a liberal order, there can still be illiberal practices, such as a female genital mutilation, ritual scarring and the physical oppression of women. Even if it is not an implication of my position that parents are entitled to kill their children, it is bad enough that horrible or harmful practices can go on within its borders. Moreover, it still leaves many vulnerable people, and particularly children, at the mercy of their groups" (Kukathas, 2002, p. 197). Such a worrisome implication is accepted due to Kukathas's perception that liberals must have a certain aversion toward attributing the authority to decide about what is morally right in a society of differing ethical standards to the states (ibid., p. 198). Clearly, coherent with his view, Kukathas does not admit the attribution of any particular value to the exercise of autonomous choices in the liberal archipelago, i.e., choices made upon reflection about which of the alternatives is the best. In his view, this would be illegitimate because not all worldviews accept the value of autonomy. He does not distinguish between autonomous choices and, 
for example, mere acceptance of the form of life in which a person is included by her birth without contemplation of the alternatives. This is why he does not attribute any duty to communities to nurture their members' capabilities to make choices (Kukathas, 2003, pp. 113-114). To clarify his point further, Kukathas offers the example of Fatima. Fatima lives in a village where her main role in her society is to be a mother and a wife. She has accepted this and she doesn't want to live anywhere else, even though there is no prohibition for her to leave her community, if she wanted to. According to Kukathas's view, Fatima is free and the society she lives in is also a free society. First, Fatima is free because she can leave if she so prefers, even if she doesn't really know that such a possibility exists (ibid., p. 113). Second, as Kukathas suggests, she is free simply because she has not rejected the life she now lives. According to Kukathas, "being free she may reject it if she so chooses; but she may not choose at all and still remain free" (ibid.).

As we see, Kukathas favours a society that only admits limited freedoms. It is, thus, not assimilable to liberal multicultural societies that ensure basic protection of rights and liberties to all citizens, as well as opportunities, for example, in the form of good education that shape possibilities to make effective choices in the society, even if one of these choices could be to live in an illiberal and inegalitarian community. Kukathas admits strong refusal of capabilities to make effective choices to live in ways not embraced by the dominant worldview of a community. Such refusal of capabilities includes even physical mutilation of members of the community (Kukathas, 2002, p. 197). Further, Kukathas clearly says that a person could be considered free "even if she is ignorant of the possibility of leaving or living differently - and simply continues to live her life" (2003, p. 203). Suffice it to say that she does not have, actually, any wish to leave the community. We think that more than what Kukathas includes in his society must be guaranteed in order to have a free society. So, one can inquire: what is further needed in order to protect the freedom of conscience?

In our view, Fatima's example apparently shows that the principle of freedom of association and the right of exit (intended merely as absence of coercion not to exit), achieve the basic goal in Kukathas's view; that of protecting freedom of conscience, in virtue of a peculiarity of the description of her condition. This description masks the difficulties of Kukathas's view because it represents a particularly favourable case, since Fatima has no dissatisfaction with her condition. There are, however, problems with his proposal when we construct the case of a person who is dissatisfied with her condition. On the basis of such a case, we claim that, in general, for the aim of protecting freedom of conscience, it is not sufficient to merely recognize freedom of association and freedom of exit. Other conditions have to exist to support such freedoms. 
To support our thesis, we build a case inspired by Joseph Raz's examples in his The Morality of Freedom (1986, pp. 373-374). This is the case of Meliha. By employing a case inspired by Raz, we do not embrace his general view which is represented by a liberal perfectionist theory that affirms autonomy as a core value (Raz, 1986). Such theory does not play any role in our argumentation. Our examples do not focus on the perfectionist value of autonomy, let alone on the defence of the perfectionist state that enforces or favours it. Our focus is on the importance of ensuring the development of capabilities that will enable members of society to make effective choices even when these choices are opposed to the worldview dominant in one's community. We consider this to be a requisite of a society protective of the right to live in accordance with conscience. More specifically, our intention is to show how not having meaningful choices when deciding to leave a community makes the exit principle Kukathas proposes as a fundamental right faulty, and the freedom to live in accordance with conscience ephemerous. If our choices are to stay in a community we do not, in good conscience, accept or to leave the community, but in a way that we also cannot, in good conscience, accept, then freedom of conscience is not protected.

\section{Absence of Coercion: Not to Leave Is Not Enough}

Meliha lives in a closed community which has no contact with the outside world and in which women have no rights, apart from the right to leave, conceded in general in the liberal archipelago. In her daily life her choices are limited (ranging from what to cook for dinner, and when to clean the house; all other choices concerning her life are made by her husband and shaped through the framework of tradition). Meliha, contrary to Fatima, is deeply dissatisfied with her life, but she does not know about the possibility of exit and about possible alternatives. So, Meliha remains incognizant and continues to live an unhappy life made up of choices that, for her, are trivial and frustrating.

She lives in a way that she cannot, in good conscience, accept. She assesses her condition as unjust and as contrary to her conception of a good life. In addition, she considers the worldview of her community as morally outrageous. She does not leave the community only because she does not know that there are other communities where she can live differently. In other words, she was misled to think that there is no such option. The important fact is that, although she was not coerced to stay in the community, she didn't really have any other choice but to stay because she did not know that there are viable satisfactory alternatives to the way women are treated in her community. Thus, the absence of coercion not to leave the community is by no means sufficient to ensure the right of exit, which is the condition for freedom of conscience. Freedom of exit must be supported by at least the substantial compo- 
nent of availability of information of at least some possible viable satisfactory alternatives. But, would this be sufficient? We think that it would not.

Let's imagine that Meliha knows about viable satisfactory alternative communities and ways of living, and she prefers them in comparison to living in her original community. She wants to leave because she can no longer, in good conscience, accept living in this community. Still, if Meliha did choose to leave, she would have to face challenges that are most likely insurmountable. To survive the journey itself without any help from the community or the outside world is nearly impossible and would most likely end in her death. Furthermore, even if her moving to her new destination were successful, there would be new dangers and harms. This is because she is unfamiliar with the outside world and unable to cope with it. Due to living in a closed community, she is deprived of the possibilities to develop skills to live in a decent way in an outside society, and, thus, she will find herself thrown into an uncharted territory facing an unknown fate. But, in order to have freedom of exit, one has to have available options that correspond to a reasonably good life. This implies a decent possibility to satisfy physical and mental valuable components of human life. These constitute absence of threat to physical integrity, conditions that sustain good health, the possibility to be engaged in social relations, as well as in activities that permit the employment of a person's talents, etc. Thus, her freedom of exit is not satisfied because of destitute alternatives.

Kukathas could reply by saying that every choice implies costs, and that we cannot expect from an association to sustain the freedom of choice of its members by saving them from all costs of leaving it. At the extreme, if my employer increases my wage in order to motivate me not to leave the job, she augments my costs of leaving. Still, it would be absurd to say that she has done something illicit (Kukathas, 2003, p. 107). But the fact that Meliha's condition implies cost is not the only problem. The problem is that all perspectives of the choice of leaving are miserable, and this is due to deliberate policies or practices of the community. The case shows that something more than the absence of coercion not to leave, joined with adequate information about alternatives, is needed. This is represented by capabilities which are needed for achieving realistic possibilities of a decent life. If freedom of conscience presupposes freedom of exit, a free society will not impede its members to acquire, and, instead, will be under the duty to sustain, the capabilities to leave by choosing among, at least, decent perspectives.

An objection can be put forward by saying that concepts of a decent life are a matter of cultural variation, and, thus, there is no neutral way to define them. This puts pressure on our requirement to allow various perspectives for a decent life as part of the freedom of exit. We think, however, that it is possible to reply to this objection. It is true that there are some variations, but, it is also true that we can rea- 
sonably identify conditions of a decent life through threats and harms to it that are universally identified as such. Like Barry says: "From the earliest times of which we have accounts of records, the things that some people have done to others in the name of punishment, revenge or sheer hatred are monotonously similar: physical pain, loss of liberty, lack of communication, denial of food and water, personal indignities (including rape by guards or soldiers), excision of bodily parts (including castration) and so on. We can deduce that these are universal bads" (Barry, 2002, p. 234). In conformity to this quotation, Barry says that there is nothing typically Western in the preference to be healthy rather than being sick, free instead of being a slave, etc. (Barry, 2001, pp. 284-291).

To illustrate the above, we can point out a dispute in India caused by vaccinating against smallpox. As Barry notes by commenting an anecdote reported by Martha Nussbaum, there has been some dissatisfaction due to the fact that the problem of smallpox was successfully resolved in India. This is because the consequence of this medical result was that the goddess Sittala Devi lost her purpose (she was the goddess supposed to protect from smallpox), and so a part of the communal culture was lost. Some thought that the cultural loss was validly replaced by the gain in public health, but the critics say that they are only victims of the typical Western binary oppositions in ways of thinking which includes the stance that it is always better to be healthy than sick. But, in fact, the universality of such a challenge may be compelling, in the abstract, to Western academics and intellectuals. Instead, the believers in Sittala Devi were no exemption from the kinds of preferences indicated by Barry because of the fact that the goddess was relevant for them in virtue of their belief that she protects them from smallpox, which indicates that health is the ultimate aim (ibid., pp. 284-285).

Until now, we have replied to Kukathas's thesis sustained by the case of Fatima, who is not presently dissatisfied by her condition, through the case of Meliha, who is presently dissatisfied by her condition. We now offer the case of Meghan, who acts as she presently judges right, that is, she is not coerced to do something that she does not, presently, accept in her conscience. In this sense, her case is analogous to that of Fatima. We will show that, nonetheless, she does not act in accordance with her conscience. This casts legitimate worries on whether even Fatima lives in accordance with her conscience.

Imagine that Meghan is a judge who condemns a person in virtue of her best judgment. Now, imagine that Meghan was manipulated, e.g., by an intelligence agency that did not permit her to be aware of all the relevant evidence. Here, we can say that something is missing in terms of whether her acting in accordance with conscience was respected. In fact, it seems that acting in accordance with the conscience of the manipulators was respected, not Meghan's. To respect acting in 
accordance with conscience does not only consist in permitting someone to act in accordance with her best judgment, or in accordance with what she thinks or feels proper, but also in avoiding to act manipulatively with the intention to orient (or disorient) her judgment, or to impede her certain behaviours. The person must be allowed to have, at her disposal, bona fide evidence relevant to form a judgment. In the absence of this, the fact that a person is not dissatisfied with what she does, or, even if she is content with what she does, is not dissatisfied with her inclusion in a practice, does not, by itself, testify that she acts in accordance with conscience. Thus, freedom of conscience does not only imply the freedom of exit, in the sense of the absence of coercion alone. It implies the development of capabilities for exit, as well as capabilities to evaluate a condition. These include, at least, information about the existence of alternatives, capabilities to have a decent life in one of the alternatives, having bona fide information about the alternatives, basic information about one's own condition, as well as capabilities to assess it.

Kukathas offers an explanation as to why, nonetheless, the group is allowed not to support the capabilities needed to leave a community, and to make critical evaluative judgments about it. This is because "honouring freedom of conscience must mean granting people the right to reject the freedom of conscience as a value" (Kukathas, 2003, p. 116). So, we have to take into account not only the conscience of dissenters, but also the conscience of the majority who may believe that the minority is in the wrong, and want to preserve the group and its integrity (ibid.). Kukathas states that such disputes over two competing claims of conscience should be settled by separating the disputing groups, even though "the terms upon which separation takes place cannot be settled as a matter of fundamental right because what is fundamentally right is what is in dispute" (ibid.). By stating this Kukathas offers reasons that make the counterexamples we have provided not enough to dispute his theory, because there is a conflict between the freedom of conscience of dissidents and mainstreamers, the latter of whom wish to protect the actual order in the community and want to deter dissenters from leaving. However, there is no room for considering Kukathas's proposal for the alleged right of the mainstreamers to obstruct the exit of the dissenters. Namely, in Kukathas's view, the right of exit is part of a theoretical construction where the only dimension of freedom that matters is represented by the possibility to choose in which kind of community to live. This is affirmed as the central political principle. Yet, this principle is inconsistent with the legitimacy to impede people to develop the capabilities needed to leave a community. In such a case, a different entitlement is advocated than the one to live in accordance with conscience. It is the right of making decisions about how others should live in accordance with their conscience. Thus, the primary conflict is not between the freedom of conscience of mainstreamers and the freedom of conscience of dis- 
senters, but between freedom of leaving a community as a condition of freedom of conscience, and freedom of others to impede the acquisition of capabilities for such a freedom, and, at the end, to impede the exercise of such a freedom. Because of the centrality of the freedom of exit in Kukathas's theory (namely, he declares it as the qualifying criterion of a free society), the opposite alleged right must be rebutted.

From the previous discussion it follows that an adequate interpretation of the right to leave a community, as a guarantee of freedom of conscience, implies that some kind of support is needed for developing the capabilities that would enable members to exit the community. Such capabilities are needed for an effective exercise of choice that we can equate with autonomy. This includes knowledge of alternatives, capabilities to critically evaluate conditions, capabilities for a satisfactory life in, at least, some alternatives one chooses. By this, we do not endorse the perfectionist view that the state needs to favour practicing autonomy. In opposition to Kukathas, we only say that the state needs to favour capabilities to exercise autonomy if one chooses to do so, as a precondition to living in accordance with conscience. But, still, there is a challenge to our thesis in Kukathas's argumentation. Namely, Kukathas claims that freedom of conscience cannot imply autonomy because the two concepts can come into conflict. In other words, sometimes acting in accordance with conscience is opposed to acting on the basis of autonomy.

To illustrate the point further, we turn to an example with Odysseus which is paradigmatic to Kukathas's view. On the other hand, the same case speaks in favour of our thesis. Odysseus wanted to hear the song of the sirens but still survive, so he tied himself up in order not to succumb to the attraction of the sirens' song and, as a consequence, renounce to travel home (ibid., p. 59). He also covered the ears of his crew. So, acting on conscience here is exactly acting against autonomy, or, at least, Kukathas says so. We have two concerns with regard to the example. First, it seems dubious to us that Odysseus would be autonomous if he succumbed to the song of the sirens. This appears more like a case of heteronomy than a case of autonomy, because it is a case of acting on an inclination and not on a deliberate choice about what is a good or right thing to do (Kant, 1785; 1996). The example only shows that, sometimes, protection of autonomy implies a temporary limitation of freedom. This happens, in the aforementioned case, because an agent knows that he would be the victim of the weakness of will to the detriment of the autonomous choice. Second, in this famous story, it was only Odysseus who clearly acted on his conscience. It is possible that the crew acted on his conscience and not on their consciences. It was Odysseus who decided that the proper goal for all is to continue travelling home. Perhaps some of Odysseus's soldiers hold the perfectionist view that, in order to live a life that deserves to be qualified as good, one must have exceptional experiences at least once in a lifetime, like the magnificent song of the sirens, even at the cost of losing the ordinary life that they would have at their arrival 
home. Who knows? Why is Odysseus allowed to make decisions instead of them? As a consequence, this is a case that can be taken as an infringement of freedom of conscience, and not as an example of freedom of conscience.

To relate this example to questions discussed by Kukathas, and to illustrate our thesis with real life cases, we observe that Odysseus's behaviour is analogous to that of parents in a repressive education closed to the input of information, or, even, in practices of mutilating children. The parents mutilate the body of children and impede them from receiving a more complete school education in order not to permit or to render some life options highly improbable, even the option to exit the community. The permission to do this means to protect only the parents as subjects of conscience, but denying the children the status of prospective subjects of conscience. By this it is not said that we favour autonomy, for example, as an element of perfection, like liberal perfectionists do (Claassen, 2018; Raz, 1986; Wall, 1998). We do not think that it is a function of the state to favour autonomous life, neither can we accept a connection between freedom of conscience and living a comprehensive autonomous life. In our view, a person could live according to conscience even by adhering to a totally illiberal community that orients all elements of her life. However, we deny that freedom of conscience is protected in a society that does not ensure capabilities to make effective choices to all members. In such a society, some live according to the conscience of the powerful in the community, not according to their own conscience. This is why we say that people must be sustained in the development of capabilities to make choices and permitted to make them, if they want to, and that this is a condition for freedom of conscience. But, if one decides to live like Fatima, this is something that a liberal state must accept without complaint. The position that we endorse is, in this regard, analogous to Barry's (2001, pp. 118-123). It partly represents an internal criticism of Kukathas's thesis, in the sense that, like him, we endorse the strong value of the right to live in accordance with conscience. Obviously, it diverges on other points. Primarily, contrary to Kukathas, we think that capabilities to make choices are a condition for the protection of the right to live in accordance with conscience. Thus, like Kukathas, we agree that a person could be free even if she lives in an illiberal context, for example, strongly constrained through religious rules, if that is her choice. But contrary to Kukathas, we argue that the right to live in accordance with conscience is protected only if capabilities to make choices are ensured. This is not satisfactory for Kukathas, even if nobody is forced to make use of these capabilities, because the conscience of the powerful members of the community is not satisfied. They are obligated to accept that some capabilities are nurtured in favour of all members of society, which they think is wrong. But this is not a valid objection. Precisely, we argue that it is sufficient to indicate a group of persons to whom it is denied to fully live in accordance with conscience, in order to show that a society is not properly respectful of freedom of 
conscience. The aim is to protect living according to conscience fairly, and not fully (which would be unrealistic). We think that the model of society that we favour can do this. It allows citizens to make choices fairly if they want to do so, or to merely accept the conditions in which they live, if they want to do so.

At the end of this part, we address a further concern regarding Kukathas's argumentation. If such a wide range of behaviour, as Kukathas wants, is allowed to the most powerful members of the group in order to protect their freedom of conscience, and freedom of conscience thus protects putting obstacles to exercise the freedom of others, why does it not include freedom to coerce them not to leave the community? Further, why wouldn't the exercise of freedom of conscience justify an additional extension of the legitimacy of coercing other people's behaviour and practices? Why are members of group A not permitted to impede people in group B to behave in a way that people in group A find sinful, if they were strong enough? Why is freedom limited inside associations and does not include freedom to interfere with the internal life of other groups? Impeding sins may be required as a demand of conscience. Why does conscience have to succumb, in this case, to the value of tolerance? It seems to us that coherence puts pressure on Kukathas's theory to threaten the principle of tolerance among communities and associations.

Finally, we remark that, in virtue of the absence of protection and support of the capabilities needed for the exercise of freedom of conscience, it is dubious what remains of such a freedom and how we should interpret it. If an association is allowed to establish public institutions or practices that disable individuals to make choices (for example, by reduced education or neglect of information that render the possible choices limited or even meaningless), then this right cannot be considered a political or social one. It seems that, in that case, we cannot claim that individuals are socially or politically free to leave. In the absence of institutions (like schools) and practices that back up such a right, what remains is just a kind of existential freedom, not a political or social one. Such freedom resembles Sartre's idea of ontological freedom which he viewed as synonymous with human consciousness, which in turn meant that humans, since they have a conscience, are always free (Sartre, 1943). Even a prisoner is free because he can choose how to react to his imprisonment. According to Sartre, human will can never have any objective restrictions. We need to distinguish that kind of existential freedom from the social or political one. If there is room for obstructing people's freedom to leave a community, Kukathas's view on freedom is more similar to Sartre's idea of ontological freedom. In fact, Kukathas states that people enjoy an "inner" freedom, that inner freedom being the liberty of conscience (Kukathas, 2003, pp. 113-114). But it seems to us that this is not enough, in the context of Kukathas's theory. He wants the freedom to leave to be the only fundamental right an individual has in a community, 
and the only protection to living in accordance with conscience. Thus, it has to be a social or political right. But, if something is considered to be a social or political right, then that fundamental right has to be guaranteed and secured by certain institutions or practices, which is not the case in Kukathas's view.

\section{A Constitutional Liberal Democracy, Or a Different Archipelago?}

Until now, we have been on the opposing side between Kukathas's liberal archipelago, distinct by an almost absolute autonomy of communities and associations, on the one side, and constitutional egalitarian liberal democracies, on the other. The former is characterized by weak constraints over associations represented only by the duties not to apply coercion over individuals who want to leave, and to tolerate other communities. The liberal constitution that we have in mind, as opposed to this society, enables the development of capabilities to make effective choices among alternative worldviews and communities that live according to them, as well as free access to information. These are some of the basic elements of an egalitarian liberal state. But these two political views do not exhaust the possible political models. We will not compare the egalitarian liberal order that we favour in opposition to $\mathrm{Ku}-$ kathas's archipelago with all possible alternatives, like, for example, some classical descriptions of the libertarian state (Nozick, 1974). This would take us too far. Instead, before concluding, we will compare the model of a political society that we favour with a kind of society that reproduces the structure of Kukathas's archipelago view, but is egalitarian. We deem that this is a more plausible view, but, nonetheless, less convincing than an egalitarian liberal constitutional democracy. Michael Otsuka (2003) is the author that we discuss now.

In contrast to Kukathas's theory, Otsuka says that there are conditions for legitimacy in an archipelago-like society of autonomous associations and communities, apart from those of uncoerced choices of group belonging and mutual toleration of groups. In Otsuka's view, the formation of different associations must not give rise to, nor preserve, inequalities in opportunities for welfare. Moreover, Otsuka requires that even in theocratic communities, education must be oriented toward the creation of knowledge to make free, rational and informed choices that permit one to choose among various political societies, as well as toward the formation of capabilities among young people that permit them to leave the political society without threats to their well-being. In the order that he proposes, "the duty [to respect freedom and equality] is fully discharged through respect for the free, rational, and informed choices of individuals which are made in circumstances of equality" (Otsuka, 2003, p. 126). In Otsuka's view, like in Kukathas's proposal, the egalitarian liberal state does not treat citizens as free, because it enforces egalitarian liberalism on its entire territory. The problem is neglecting that citizens who live inside 
the borders of the state can form a subpopulation that decides to govern itself in a way that is not egalitarian liberal. But, treating agents as free means accepting their right to freely associate on the terms that they choose, even if they give rise to illiberal societies. Otsuka rejects the objection that the liberal archipelago is factually impossible. He sees no barriers for the transformation of the actual states in confederations of voluntary associations where citizens "are allowed to migrate into uninhabited areas and establish the illiberal or inegalitarian societies imagined above" (ibid., p. 129). In such a confederation, even the problem of the cost of migration represented by losing personal ties would disappear. Such a cost would not be greater than changing the place of living (from London to Manchester, for example) in a single state. Still, we resist that proposal, even if we think that it is a more plausible candidate than Kukathas's archipelago. Our objection is that the system is unstable, or contradictory, in virtue of an observation offered by Otsuka. He admits that the obligations to sustain the capabilities to make effective choices he puts on the illiberal and hierarchical confederative units of the liberal archipelago can threaten their persistence (ibid., pp. 120-121). When people have capabilities to make effective choices, the survival of the community and its worldview is in danger, not to mention its capacity to flourish, because of the real risk that members will leave or that they will transform the worldview of the community. But, then, we can expect that the leaders of such communities will reject such obligations. Their primary motivation is to protect the survival and flourishing of their communities and their worldviews. We cannot expect that illiberal communities will persistently and coherently voluntarily protect Otsuka's robust view of freedom of association and of leaving the actual community in which one lives.

The abuse of the ruling elite that can happen in practice is not the only problem. This is a danger present in constitutional democracies, as well, like we see in current events in some of the states that have embraced this political order (i.e., Hungary, or Poland). The difference is that liberal states have mechanisms to obstruct such degenerations at their foundational level and basic structure. Unfortunately, such obstacles are not an absolute guarantee, but, at least, they are a resource coherent with the order. Namely, in such states abuses of political elites infringe the constitutional values of their states that are a fundamental part of the worldview and of the foundational principles of such societies. Although the states cannot be empirically absolutely stable, in the sense that they, in fact, do not have absolute protection from subversion, they can be stable, at least, in the sense that they can coherently activate protective mechanisms. The conception is clear: there are some basic rights, liberties and opportunities that support capabilities needed for the exercise of freedom of conscience. There is a state that protects them through its basic constitution, its legal mechanisms and its institutions. There are associations that live in accordance with their worldviews, provided they do not harm capabilities to leave the associa- 
tion when one chooses to do so. The state has the legitimacy to intervene when these capabilities are violated. On the other hand, Otsuka's conception is not so clear. The basic question is: who has the legitimacy to intervene when the robust support for the capabilities to leave the association is violated?

It seems coherent with Otsuka's position that such mechanisms are present in the associations themselves. But it is very difficult to expect that this could happen in practice. In the illiberal and hierarchical communities in Otsuka's archipelago, by the abuse of power, in fact, political elites show loyalty to the worldview dominant in their association. This is because, like Otsuka admits, the substantive freedom of exit endangers the survival or flourishing of such communities. In virtue of this serious threat, the ruling group expresses loyalty to their community's worldview if they abolish robust freedom of exit. This is, consequently, like Kukathas says, their act of conscience that we can expect from them in the name of the worldview of their community, and not merely consider as abuse, as we do in constitutional democracies. Thus, it seems that we need a state that has a central statute that establishes basic rights, liberties and opportunities needed for capabilities for an effective freedom of exit, and that has the power to enforce them. Such capabilities represent a robust requirement, in Otsuka's view. Like we see above, it includes, for example, good education, and capabilities for welfare in contexts external to the association. But, if such centralized power is legitimate, one can ask what is the difference between such a view and a liberal society that accepts huge variations inside associations and communities because it is shaped in accordance with a political liberal conception, like Rawls's (2005), centred only on the basic structure of society, instead of a comprehensive liberal conception that interferes deeply with the lives of its members?

Finally, in our view, Otsuka's archipelago is unstable because it either does not include the mechanisms needed to protect basic capabilities for an effective exercise of freedom of conscience that will likely be under pressure of denial inside some associations, or it does have such mechanisms. In the latter case, however, the difference between such a society and a state shaped in accordance with a political liberal conception is not visible (Rawls, 2005). A further problem has to do with the question about where these archipelago political societies would arise. Otsuka speaks about migration into uninhabited areas. But, do these uninhabited areas exist, for example, in Europe or America? Perhaps in some states they do, but we cannot expect that we will typically encounter such areas. We can find some sporadic rearrangements of borders which are more or less far from voluntary. As the real world indicates, such rearrangements, however, are hardly peaceful and made in toleration. On the contrary, they are, usually, sources of conflicts, and even of wars with all the tremendous consequences. 


\section{Conclusion}

We develop our discussion without questioning Kukathas's commitment to the right to live in accordance with conscience as the fundamental normative constraint. However, we arrive to very different conclusions. The most general source of divergence is related to the scope of the ambition to protect freedom of conscience. Kukathas's ambition is to offer a full protection of the right to live in accordance with conscience to all persons. We think that this ambition compromises the effectiveness of this right. If the right is fully protected for intolerant persons whose conscience requires, for example, impeding alleged sinful ways of life, and, even, obstructing the acquisition of capabilities needed to live in accordance with them, then, for some other persons, the right will be only declarative, or ephemerous. This is true even if the freedom of association and exit is protected from coercion, like Kukathas requires. Namely, if some persons are only protected from coercion, but are deprived of the needed capabilities, they will not have the effective possibility to exercise the right to live in accordance with conscience. Among such capabilities, there are those needed for exercising satisfactory choices, including the information about alternative suitable options. This implies a liberal state that ensures some liberal rights to all, instead of Kukathas's archipelago. Obviously, this will be unsatisfactory for all those whose conscience requires them not to allow such choices because they deem them, for example, as sinful or disruptive of tradition. They will not be able to fully live in accordance with their conscience. But this shows that $\mathrm{Ku}-$ kathas's ambition is not realistic. Instead of the ambition to fully protect freedom of conscience for all, the realistic aim is to protect such freedom fairly. Kukathas's archipelago does not realize this aim.

Archipelago liberalism is not an attractive perspective because of the insufficient warrant to effective freedom of persons. As a consequence, instead of being a form of society protective of freedom of conscience, it renders its protection contingent on the will of the powerful. In fact, like we have shown, it is more of a threat to freedom and equality than a protection. This is more visible and real in Kukathas's proposal, in virtue of the absence of some elements of equality that can be found in Otsuka's theory. The advantages of the latter model are present in virtue of its egalitarian elements that render freedom effective.

The further question that can be asked is why the egalitarian liberal state is better than Otsuka's egalitarian libertarian archipelago? In our view, the advantages are represented by the instability of the society described by Otsuka. In order to offer effective protection of freedom, this society collapses into a constitutional liberal democracy. 


\section{REFERENCES}

Barry, B. (2001). Culture and Equality: An Egalitarian Critique of Multiculturalism. Cambridge, Polity Press.

Barry, B. (2002). Second Thoughts - and Some First Thoughts Revived. In Kelly, P. (ed.), Multiculturalism Reconsidered. Culture and Equality and Its Critics. Cambridge, Polity Press, pp. 204-238.

Claassen, R. (2018). Capabilities in a Just Society. A Theory of Navigational Agency. Cambridge, Cambridge University Press.

Kant, I. (1785; 1996). Groundwork of the Metaphysics of Morals. Cambridge, Cambridge University Press.

Kukathas, C. (1992). Are There Any Cultural Rights? Political Theory, 20(1), pp. 105139.

Kukathas, C. (2002). The Life of Brian, or Now for Something Completely DifferenceBlind. In Kelly, P. (ed.), Multiculturalism Reconsidered. Culture and Equality and Its Critics. Cambridge, Polity Press, pp. 184-203.

Kukathas, C. (2003). The Liberal Archipelago. A Theory of Diversity and Freedom. Oxford, Oxford University Press.

Mill, J. S. (1859). On Liberty. London, Parker, Son \& Bourn.

Mill, J. S. (1861). Utilitarianism. London, Parker, Son \& Bourn.

Nozick, R. (1974). Anarchy, State, and Utopia. New York, Basic Books.

Otsuka, M. (2003). Liberalism without Inequality. Oxford, Oxford University Press.

Rawls, J. (1999). A Theory of Justice. Oxford, Oxford University Press.

Rawls, J. (2005). Political Liberalism. New York, Columbia University Press.

Raz, J. (1986). The Morality of Freedom. Oxford, Oxford University Press.

Sartre, J.-P. (1943). Being and Nothingness. A Phenomenological Essay on Ontology. London, Routledge.

Wall, S. (1998). Liberalism, Perfectionism and Restraint. Cambridge, Cambridge University Press.

Mailing Addresses:

Elvio Baccarini, Professor at the Faculty of Humanities and Social Science, University of Rijeka, Sveučilišna avenija 4, 51000 Rijeka, Croatia.

E-mail: ebaccarini@ffri.hr

Julija Perhat, PhD candidate, Faculty of Humanities and Social Science, University of Rijeka, Sveučilišna avenija 4, 51000 Rijeka, Croatia.

E-mail: julija.perhat@gmail.com 